1

\section{2 local cycling prevalence}

3

Anna Goodman and Rachel Aldred

4

5

6

7

8

9

\section{Abstract}

\section{Keywords}

\section{Background}

\title{
Inequalities in utility and leisure cycling in England, and variation by
}

Accepted author version of a paper published in Transportation Research $\mathrm{F}$ here:

https://www.sciencedirect.com/science/article/pii/S1369847817302802

This paper analyses Active People Survey data (collected 2011/12 to 2015/16) on 789,196 English

adults, providing new information on how a range of socio-demographic factors are associated with utility and leisure cycling. Substantial inequalities are found in relation to gender, age, disability, and ethnicity for both types of cycling. For gender and age, and perhaps for disability in relation to recreational cycling, inequalities are moderated by local cycling prevalence such that English authorities with more cycling see less inequality. For education and car ownership, the picture is more mixed. Individuals with higher educational levels are more likely to participate in leisure cycling, but within most English local authorities this association is absent for utility cycling. Car ownership is negatively associated with utility cycling, but positively associated with recreational cycling. The paper's discussion section puts these inequalities in context, and discusses the significance of the fact that some inequalities seem to be less pronounced or even absent in some contexts. It is argued that more research and a broader conceptualisation of cycling inequalities are needed to better understand and address inequalities in cycling participation.

Active Travel; Cycling; England; Equity; Sustainable Transport

This paper uses Active People Survey (APS) data to examine inequalities in cycling in England, both for utility and for leisure. Research on demographic variation in cycling has tended to focus on age, gender, and income or educational level, finding that differences are highly contextual. In a review of 
1

2

3

4

the literature on cycle commuting, Heinen et al (2010: 69) conclude: 'It appears that the impact of gender on cycling is country specific. [...] While a relationship between age and cycling evidently exists, it is unclear whether it is a universal one [and the] relationship between cycling and income is even less clear.' Less research examines other socio-demographic variables. However, studies have found lower transport cycling participation rates among some (but not all) ethnic minority communities in contexts including the Netherlands and USA (Fishman et al 2015, Nehme et al 2016, People for Bikes/Alliance for Biking and Walking 2016).

In England, research has focused on age and gender variation in cycling, finding substantial inequalities for both groups in commute and other utility cycling (Department for Transport, 2016; Office for National Statistics, 2014) as well as inequalities in participation by disability (Andrews et al 2018). In English local authorities with higher cycling levels, age and gender inequalities are reduced (Aldred et al 2016). Fishman (2016) reports that similar patterns apply across countries, with at the other end of the spectrum mode share for cycling being slightly higher for women than men in the Netherlands. This suggests that places with higher cycling levels have achieved greater success in meeting women's and older people's cycling needs than those places where cycling is lower. Building on such work this paper examines the extent of variation in relation to overall cycling participation by age and gender, and by ethnicity, educational status, car ownership, disability, and co-resident children in a household. There are potential implications for policy - for instance, the extent to which there are lessons to learn about overcoming different inequalities from more successful English cities, and/or from other countries and cities. The paper also moves debates on cycling equity forward by going beyond a focus on cycle commuting to consider all cycling in England, both leisure and utility, and how any inequalities differ between the two types of cycling. Non-commuter and leisure cycling are relatively under-researched (Goodman et al 2013) partly because of a lack of data. In particular, there is little research on demographic correlates of leisure cycling, although it is sometimes hypothesised as a potential route into regular utility cycling (Jones 2001). Might movement from leisure to transport cycling help diversify cycling participation, or not? 
1 The analysis here can help to consider the extent to which this is the case - for instance, if

2 recreational cycling is currently more equal than utility cycling.

3 This paper has two broad aims. Firstly, it examines the magnitude of cycling inequality across

4 demographic and socio-economic groups, for total cycling, recreational cycling, and utility cycling.

5 We additionally examine how far any inequalities differ between recreational versus utility cycling.

6 Secondly, we examine how far any inequalities differ with respect to the prevalence of cycling in the

7 local authority in question, testing the hypotheses that inequalities will be lower in local authorities

$8 \quad$ with a higher overall cycle mode share.

9 2. Methods

\subsection{Data source: Active People Survey}

11 We drew on data collected in the Active People Survey (APS), a rolling national survey examining

12 participation in sport and activity among adults in England. APS collects data on around 500 people

13 each year for each local authority in England. The only exceptions are the very small local

14 authorities of City of London and Isles of Scilly, which have an annual sample size of around 80 each,

15 and which we combined with Westminster and Cornwall respectively.

16 APS samples participants using random digit dialling, and administers the survey over the telephone

17 (Sport England, 2017). In households with more than one person aged 16 or over (i.e. eligible to take part in the survey), one respondent was randomly selected using the method described by Rizzo et al. (2002). We pooled five years of APS data from October 2011 (when both our cycling outcome variables were first collected) to September 2016. The overall response rate across this period was $26 \%$. After excluding $4 \%$ of participants with missing data, this gave a total sample of 789,196 adults aged 16-99. 


\subsection{Variables}

\section{Outcomes: Cycling Participation}

APS asked all participants 'On how many days in the last 4 weeks have you done any cycling?'

Participants who reported any cycling were further asked "Can I ask on how many of those days

were you cycling for the purpose of health, recreation, training, or competition not to get from place to place?" From these questions we derived two measures of cycling participation:

1. Proportion of adults doing any cycling in the past four weeks.

2. Proportion of adults doing any recreational cycling in the past four weeks.

3. Inferred proportion of adults doing any utility cycling in the past four weeks. An adult was counted as having done any utility cycling if the number of days they reported of cycling was greater than the number of days reported of recreational cycling.

Our measure of utility cycling is expected to underestimate total utility cycling, as it will not capture an individual who engaged in utility cycling for the same number of days that they engaged in recreational cycling. Comparisons with the National Travel Survey (2011-2016), however, indicate that the extent of this underestimation is likely to be modest. For example, the proportion of people estimated to make one or more utility trips per week in APS is $4.6 \%$, very similar to the $4.3 \%$ of National Travel Survey participants reporting any past week utility cycling in their travel diary.

\section{Correlates of Cycling Participation}

We examined cycling inequalities with respect to the seven participant characteristics listed in Table 1: sex; age; ethnicity (white/non-white), physical disability (no/yes), education, household car ownership (no car/any car in household), and whether the participant had a co-resident child aged 5-15 (no/yes). We considered that children under 5 were relatively unlikely to be doing much ownbicycling, but that children aged 5 and over might have a larger effect on the likelihood of their carers/parents cycling.

Highest educational qualification was categorised as 'low' (Levels 1 or 2 (GCSE-level) or below, or 'other'), 'medium' (Level 3 (A-Level-equivalent) or apprenticeship), or 'high' (Level 4 upwards). Co- 
1

2

3 4 years living with a sibling aged 15 years).

5

6

7

8

9

\subsection{Statistical analyses}

resident children aged 5-15 were defined as children between those ages who lived in the same household as the participant and were at least 16 years younger than the participant. This latter restriction was put in place to exclude participants living with siblings (e.g. a participant aged 18

Information on sex, age, ethnicity, disability and having a co-resident child was collected in all five years of APS. Data on education was collected on the full sample in 2011/12, and on a random subsample in 2012/13 (50\% of participants) and 2013/14 (25\%). Data on car ownership was only available on a random $50 \%$ of participants in $2011 / 12$. For all seven variables, missing data among those who were asked the relevant question was $<2.5 \%$. In our analyses, we excluded the $4 \%$ of participants missing data on sex, age, ethnicity, disability or having a co-resident child.

For education and car ownership, we further restricted our analyses to participants with data on the variable in question. When making comparisons in relation to having a co-resident child, we restricted our analyses to participants aged 24-58 years, ages between which the proportion of adults with a co-resident child age 5-15 was at least $5 \%$. The dataset does not specify parental relationships between child and adult household members. However, by restricting the age range in this way, we sought a) to limit the potential for residual confounding by age and b) to facilitate interpretation by restricting our comparisons to households where the child in question could generally be expected to be the offspring of the adult, as opposed to a grandchild.

To address our first aim, we present national data for England on the cycling participation of different groups and the associated prevalence ratio. We did this for each of the seven participant characteristics of interest, for each of the three cycling outcomes in turn. We estimated prevalence ratios using Poisson regression with robust standard errors (Zou, 2004). We chose this in preference to logistic regression because the latter does not provide a good approximation of the relative risk for common outcomes. In calculating the prevalence ratios, we adjusted for the participant's sex, age, and ethnicity. To assess the potential effect of mutual adjustment for all seven characteristics, 
1

2

3

4

we repeated our analyses restricted to the $10 \%$ of participants who had been asked questions on education and car ownership.

After first calculating prevalence ratios separately for recreational and utility cycling, we then examined whether there was evidence of a difference in cycling inequalities between these two forms of cycling. To do this, we appended together two copies of our dataset with 'cycling for recreation' as the outcome in one and 'utility cycling' as the outcome in the other. We then tested for interactions between the participant characteristic in question and whether the cycling outcomes was recreational or utility cycling, adjusting for the clustering of two records within each participant. To address our second aim, we examined the association between overall cycling participation (the predictor) and the magnitude of any inequality of cycling (the outcome) at the level of the local authority. To do this we calculated for each local authority separately a) the proportion of individuals doing any cycling in the past four weeks and b) the prevalence ratio for cycling participation for the participant characteristic and cycling measure in question, adjusted for sex, age, and ethnicity. We then used linear regression to examine the association between these two variables, with local authorities as our units of analyses.

For each characteristic, we restricted our analyses to the subset of local authorities that contained at least three individuals in every cell - for example, when looking at gender differences, we required there to be at least three female cyclists and three male cyclists for each of our three cycling outcomes in the local authority in question. Only 36/324 local authorities met this criterion in relation to car ownership (versus 155-324 for the other six characteristics), and we therefore did not examine car ownership in relation to our second aim.

All our analyses took account of the fact that the APS sample is stratified by local authority. APS provides weights that adjust for differential response rates by gender, age, working status, ethnicity, size of household, and occupational social class. Different weights are provided for analysis at the local authority and at the national level, and are suitable for combination across years. We applied these weights such that, when each local authority was weighted equally when conducting analyses 
1

at the level of local authorities, whereas each local authority was weighted by its population size when conducting analyses at the national level. All analyses used Stata 14.1.

\section{Results}

\subsection{Inequalities with respect to gender and age}

As shown in Table 2, there were marked inequalities nationally in cycling participation by sex, with women approximately half as likely to have done any cycling in the past four weeks as men (adjusted prevalence ratio 0.49). Looking at recreational versus utility cycling separately, there were large gender inequalities for both but a larger difference for utility cycling (prevalence ratio 0.42 versus 0.51 for recreational cycling, $\mathrm{p}<0.001$ for interaction). There were marked inequalities in cycling participation by age, with the probability of doing any cycling declining rapidly after age 50 . Once again, there was evidence that the pattern of the decline with age differed between recreational cycling utility cycling.

Specifically, utility cycling decreased steadily with older age, whereas recreational cycling peaked among participants in their forties before then declining at older ages. This middle-aged peak in recreational cycling seemed to be mediated by having a co-resident child age 5-15: after adjusting for having a child, the prevalence ratio for recreational cycling attenuated among individuals in their thirties and forties, and became similar to that seen age 16-29 (see Appendix 1). Otherwise, the prevalence ratios shown in table 2 for sex and age were very little changed after additionally adjusting for disability, having a child, education and having a household car.

Table 3 examines how the representation of female cyclists and older cyclists varied between local authorities with lower versus higher overall levels of cycling. As Table 3 shows, there was strong evidence of a positive association between the prevalence ratio for female versus male cycling and the overall cycling prevalence, i.e. female representation increased in local authorities with higher cycling levels. This is illustrated by the black line in Figure $1 \mathrm{~A}$, which shows that the prevalence ratio for females doing any cycling rose from an average of 0.38 in local authorities in which $\leq 10 \%$ of 
1 adults had cycled in the past four weeks to 0.61 in local authorities in which $20 \%+$ of adults had

2 cycled.

3 Moreover, as the overall level of cycling increased, female representation increased faster for utility

4 cycling than for recreational cycling, narrowing the difference between these two types of cycling

$5 \quad(p<0.001$ for interaction; compare blue versus red lines in Figure 1A). Similar findings were observed

6 with respect to older cyclists: the representation of older cyclists increased in local authorities with a

7 higher overall cycling prevalence, and the prevalence of this increase was somewhat stronger for

$8 \quad$ utility cycling than for recreational cycling.

9 Yet despite this increasing representation of females and older people, large gender and age gaps

10 remained even in the local authorities with the highest overall cycling levels. Nationally, the

11 prevalence ratio for female cycling was below 1 in all English local authorities (range 0.25-0.91). The

12 prevalence ratio for cycling by older people (aged 50+) was well below 1 in all English local

13 authorities (range 0.21-0.77).

\subsection{Inequalities with respect to other demographic and socio-economic characteristics}

Non-white individuals were around half as likely as white people to have cycled in the past four weeks (Table 2). These results changed very little after adjusting for additional characteristics (see Appendix 1), and the same was true for all other results discussed in this section except where otherwise indicated. The ethnic difference was larger with respect to recreational cycling than for utility cycling, although marked differences were observed for both. There was no evidence that the underrepresentation of non-white individuals varied according to overall cycling levels in the local authority (Table 3; Figure 1C). This analysis was however less well powered than other contrasts presented in Table 3 because of the small non-white population in many local authorities. People with a physical disability were around half as likely to have cycled in the past four weeks, and this effect was very similar for recreational and utility cycling (Table 2). In comparisons across local authorities, there was some evidence that the representation of disabled individuals among recreational cyclists increased in local authorities with higher overall cycling levels, whereas the 
1

2

3

4

5

6

7

8

9

opposite trend was observed with respect to utility cyclists ( $p=0.009$ for interaction). Regardless of the overall level of cycling in the local authority, the average prevalence ratio for cycling among people with a disability was far below parity (Figure 1D).

Individuals with a co-resident child aged 5-15 were considerably more likely to have cycled recreationally in the past four weeks, and were also somewhat more likely to have cycled for utility purposes (Table 2). There was a trend towards the magnitude of this difference becoming smaller in local authorities with a higher prevalence of cycling, although this was only marginally statistically significant $(p=0.05$, Table 3$)$.

A lower level of education was progressively associated with a lower probability of having cycled for recreational purposes in the past four weeks (Table 2), and there was no evidence that this effect varied according to the overall prevalence of cycling in the local authority (Table 3 ). In the national analyses, lower education was also associated with a lower probability of having cycled for utility purposes in the past four weeks (prevalence ratio $0.76,95 \% \mathrm{Cl} 0.72-0.80$, for those with low/medium education versus high education). Interestingly, however, this association was not evident in analyses at the level of local authorities: across the 317 local authorities included in Table 3 , the average prevalence ratio for those with low/medium versus high education was $1.06(95 \% \mathrm{Cl}$ $0.98-1.13)$.

This contrasted with the findings for all other variables considered, for which the association at the national level was qualitatively similar to the average across local authorities. The explanation for the discrepant findings is that there exists a fairly strong association between utility cycling and education at the level of the local authority, with higher average levels of education observed in high-cycling places like Cambridge, Oxford and York ( $r=0.46$ for correlation between $\%$ utility cycling and \% with high education across the 317 local authorities included in Table 3). This creates an association between education and utility cycling at the national level that is not observed within most local authorities. Indeed, individuals with low or medium education were in fact slightly more likely to have engaged in utility cycling in local authorities with average or below-average levels of 
1 cycling. Only in those local authorities with the highest levels of cycling were individuals with high

2 education more likely to have cycled for utility purposes in the past four weeks.

3 Finally, having a car in the household was associated with a higher probability of having done

4 recreational cycling in the past four weeks, and a lower probability of having done utility cycling

5 (Table 2). This association in relation to recreational cycling attenuated slightly after adjusting for

6 educational level, but nevertheless remained large (prevalence ratio 1.43, see Appendix 1). Because

7 data on car ownership was not available for most participants, it was not possible to examine how

8 these associations varied in relation to the overall level of cycling in the local authority.

4. Discussion

\subsection{Summary of findings}

We observed notable differences in the probability of cycling across demographic groups, with pastmonth cycling being independently predicted by being male, younger, white, without a physical disability, more educated, and living with a child age 5-15. These effects were all observed for both recreational and utility cycling, but there was often evidence of larger differences for one type of cycling than the other: e.g. utility cycling showed larger differences in terms of gender and age, but recreational cycling showed larger differences in terms of ethnicity and having a child age 5-15. In the case of car ownership, the nature of the association with recreational versus utility cycling was qualitatively as well as quantitatively different: having a car in the household is positively associated with recreational cycling but negatively associated with utility cycling.

\section{Comparisons across local authorities}

21 In line with Aldred et al (2016), the magnitude of the inequality by age and gender was smaller in local authorities with higher overall cycling levels. This was particularly noticeable in relation to utility cycling (i.e. the type of cycling that showed larger age and gender differences). Nevertheless, even in local authorities with relatively high levels of cycling, marked age and gender differences were still apparent. Otherwise there was generally no evidence that the magnitude of inequalities reduced in local authorities with a higher prevalence of cycling, with the exceptions of weak 
1

2

3

4

5

6

7

evidence that this was true in relation to recreational cycling and having a disability, and in relation to total cycling and having a co-resident child.

With respect to education, the national association between higher education and a higher probability of doing utility cycling was largely driven by the fact that cycling levels were higher in local authorities with a higher average level of education (e.g. Cambridge and Oxford). Within local authorities, this association was not systematically observed: indeed, in most local authorities the association was reversed and there was a trend for less educated people to have a higher cycling level. Only in the local authorities with the highest cycling levels (again, such as Cambridge and Oxford) did the within local authority pattern of cycling match the national picture of higher education being associated with higher cycling.

\subsection{Gender and age differences in cycling}

Gender and age are two dimensions of equity that have been relatively well studied previously (e.g. Aldred et al 2016, 2017). Patterns found previously in relation to commuting were replicated here, with higher-cycling local authorities showing more gender and age diversity in cycling. However, this does not necessarily mean that growth in cycling will automatically bring more age and gender equity (Aldred et al 2016). Our data did not span a long enough time period to reliably investigate this, unfortunately.

Nonetheless, we see clear evidence that in England, authorities exist with greater age and gender equity in both leisure and utility cycling, including by gender up to parity and by older age up to a prevalence ratio of 0.77 . These authorities have a comparatively high overall level of cycling.

Presumably, they are places where people in general are better supported to cycle - whether by infrastructure and/or culture. This support is particularly important in encouraging women and older people to cycle, whereas in most of England these groups may be disproportionately excluded, for instance by stronger preferences for higher quality infrastructure (Winters and Teschke 2010). While generally the gender gap is greater for utility than leisure cycling, as all cycling grows, female 
1

2

3

4

5

6

7

8

9

representation in utility cycling grows faster than for leisure cycling. In other words, these are also places where female utility cycling is relatively well supported.

Recreational cycling peaked in middle age, and this increase between young adults and middle-aged adults seem to be explained by the presence of a co-resident child aged 5-15. In other words, the reason why middle-aged people are more likely to participate in recreational cycling than younger adults is that they are more likely to have a child in the household. Potentially, adults with young families might constitute a 'new market' open to utility cycling (Jones 2001). In high-cycling countries riding with children is an attractive and flexible alternative to motorised transport (Eyer and Ferreira 2015). However, utility cycling with children is likely to require particularly high-quality infrastructure and supportive cultural norms (Aldred 2016), so this is probably not yet a 'near market' in much of the UK. Indeed, the slight decline in relative cycling participation among people with a child aged 515 in the household as cycling increases suggests that current (infrastructural/cultural/policy) support for cycling is currently not at such a standard, even in the 'best' English contexts.

\subsection{Association of other demographic factors with cycling}

\section{Ethnicity}

Within the UK, there has been little discussion of cycling and ethnicity; partly because survey samples often include relatively few non-white individuals which limits any ability to make comparisons. In our unusually large sample size, we found a lower participation of non-white people in cycling; non-white people being around half as likely as white people to have cycled in the past four weeks. This relationship was stable, changing little when adjusting for additional characteristics, and not varying between low-cycling local authorities and higher-cycling authorities. The disparity between non-white and white people was higher for recreational cycling, suggesting that encouraging existing recreational riders into utility cycling will do nothing to reduce this inequality. 
1 Why are non-white English residents only around half as likely to cycle as white English residents? In

2 higher-cycling countries such as the Netherlands ${ }^{1}$ many authors identify a similar pattern (e.g.

3 Fishman et al 2015, van der Kloof, 2014). Its magnitude is however smaller than the (stable by

4 cycling prevalence) gap found in England. People of non-Western ethnicity living in the Netherlands

5 make $22.8 \%$ of their trips by cycle, compared to $27.9 \%$ for white Dutch people - an underrepresentation, but far lower proportionately than the gap in England. Fishman et al (2015) found those of non-Western ethnicity gaining $17 \%$ fewer MET hours from cycle trips, with this gap partially attenuated by more MET hours gained from cycling to public transport. In England, as in the Netherlands, where cycling and ethnicity has been discussed it has mainly been in relation to (i) cycling as culturally alien to non-white Britons and/or (ii) bicycles as a status threat for marginalised groups (e.g. Steinbach et al 2011). This is a 'deficit model' where often the reason for not cycling (implicitly or explicitly) lies within the minority community. While not necessarily entirely incorrect, a sole focus on minority culture neglects other potentially important issues: (i) the locations where public and private organisations provide cycle infrastructure and services, the types of trip they serve, and the inclusivity of those services, and (ii) the impact of the attitudes and behaviour of other communities (and of service providers). These are under-researched in the literature. However, in relation to (ii) a report on increasing cycling among Asians in Lancashire (Bowles Green Limited 2008: 14) states: 'Some areas of East Lancashire have almost 100\% white ethnic population (for example Higher Croft, Meadow Head, Millhill, Roe Lee and Shadsworth); these are effectively 'no-go areas' for people from Asian ethnic communities. Provision of cycle routes must take this factor into account.'

This paragraph represents a rare suggestion in the European academic and policy literature that fear of racial harassment could be a barrier to cycling. By contrast, academic literature does discuss the

\footnotetext{
${ }^{1}$ Of course, 'non-white' or 'non-Western' is an immensely diverse category and groups covered will vary substantially within regions or countries.
} 
1

2

3

4

impact of (fear of) harassment and crime on ethnic minority communities using public space as pedestrians (e.g. Zempi and Chakraborti 2015) or public transport (e.g. Palacin et al 2016). Writing from Australia Stanley and Vella-Brodrick (2009) comment that:

'The experience of racism on public transport is a driver in social exclusion [leading to] the avoidance of use of public transport, even where people had few other travel options.'

Writers in the USA have started discussing a related phenomenon of 'Biking While Black' (e.g. Cox 2016). This, like safety concerns that may disproportionately affect women's cycling, is an underresearched area within transport studies compared with traffic danger (which unlike racial and sexual harassment, also has a substantial effect on white men). Alternatively, or in addition, England, like the USA, may have seen a 'bias towards increased cycling infrastructure investment in areas of existing or increasing privilege' (Flanagan et al 2016).

\section{Disability}

People with a physical disability were around half as likely to have cycled in the past four weeks, and this effect was very similar for recreational and utility cycling. In comparisons across local authorities, there was some evidence that the representation of disabled people among recreational cyclists increased in local authorities with higher overall cycling levels, whereas the opposite trend was observed with respect to utility cyclists.

Cycling and disability is an under-researched area (Clayton et al 2017, Andrews et al 2018). As with people of non-white ethnicity, a substantial relative difference (a 50\% decrease in likelihood of cycling) persists both in higher- and lower-cycling areas. However, as with ethnicity, this does represent substantial variation in absolute levels of cycling by disabled people, given the variation across the country (e.g. $2.5 \%$ of disabled people had cycled in the past 4 weeks in the three lowestcycling local authorities, compared to $22.8 \%$ in the three highest-cycling authorities). It may point to additional interventions needed to get more disabled people cycling, in addition to broadly more supportive infrastructure and cultural environments for cycling. For example, adapted cycles for disabled people, including e-bikes, are often substantially more expensive than standard cycles, 
1

2

3

4

5

6

7

8

9

raising issues of affordability (and vulnerability to theft). As with gender and ethnic imbalances in cycling, (fear of) harassment, crime or discrimination may affect participation in, and comfort with cycling. Such experiences may be compounded by built environment obstacles that disproportionately affect disabled people (Gaete-Reyes 2015). For example, cycle routes in England frequently feature barriers that necessitate cyclists being able to push or even carry their bikes, impossible for many disabled cyclists (Clayton et al 2017).

\section{Education}

A lower level of education was progressively associated with a lower probability of having cycled for recreational purposes in the past four weeks, and there was no evidence that this effect varied according to the overall prevalence of cycling in the local authority. In the national analyses, lower education was also associated with a lower probability of having cycled for utility purposes in the past four weeks. However, this national result was driven by an ecological association at the level of the local authority, such that higher-cycling local authorities tended also to have more educated populations.

Within local authorities, there was no systematic evidence that more educated people were more likely to cycle than less educated people. Indeed, in low-cycling local authorities the trend was in the opposite direction, with higher levels of cycling among less educated individuals. This may be related to differing cultural perceptions of cycling in different local areas (Bonham and Suh 2008, Aldred and Jungnickel 2014). For example, cycling in affluent university cities such as Cambridge and Oxford may be seen as more suitable for higher-status individuals than cycling in lower-income cities such as Hull, where it remains associated with poverty and deprivation.

Taking educational level as an imperfect proxy for income, these findings are interesting as they counteract assumptions about utility cycling being concentrated among higher-income groups. These results suggest that while this may be true for recreational cycling, it is not necessarily the case for utility cycling. The image of cycling as a middle-class pursuit so recently prevalent in the UK press ("the new golf": Wallop 2016; "white, male and middle-class": Hill 2015) may stem from the 
1 imbalances in recreational cycling or the high levels of cycling in places such as Cambridge; or indeed

2 from take-up of cycling (recreational and/or utility) among journalists. Portraying utility cycling as

3 the preserve of the highly-educated middle-class misrepresents the local picture in many parts of

4 the country, however.

5 Car Ownership

6 Finally, having a car in the household was associated with a higher probability of having done

7 recreational cycling in the past four weeks, and a lower probability of having done utility cycling. The

8 implications for policy are mixed. Getting recreational riders cycling more for utility purposes might

9 reduce car trips; however, as with the educational findings suggested above, it may also serve to

10 concentrate utility cycling among more privileged groups. Increasing recreational riding may in turn

11 increase car trips, as for some leisure activities the car is used to access the place of recreation

12 (Goodman et al 2012).

This paper has explored inequalities in cycling participation, looking at a range of dimensions and covering both recreational and utility cycling. In different contexts (within and outside England) many of these inequalities do not appear, or are attenuated, implying that they are not necessarily inevitable. However, while some high-cycling local authorities in England have succeeded in attenuating age and gender disparities in cycling, other demographic inequalities identified here persist in authorities with higher levels of cycling. The paper suggests that there may be a range of reasons for these inequalities, and that policy may address (or indeed reinforce) these barriers. More research should be conducted into the various barriers that lead to lower cycling rates among different groups. Although policy can help address these barriers, given the relative paucity of research it is not always easy to put together policy packages aimed at reducing cycling inequalities. This paper has made a start in this regard by identifying cycling inequalities in England (and, in the case of education, of identifying a variable which, contrary to popular belief, is not associated with 
1

2

3

4

5

6

7

8

9

substantial inequalities) and the extent to which they are reduced in contexts of higher cycling, and suggesting some potential reasons for this and avenues for further investigation.

\section{Bibliography}

Aldred, R., Elliott, B., Woodcock, J. and Goodman, A. (2017) Cycling provision separated from motor traffic: a systematic review exploring whether stated preferences vary by gender and age, Transport Reviews 37 (1), 29-55

Aldred, R., Woodcock, J. and Goodman, A. (2016) Does more cycling mean more diversity in cycling? Transport Reviews 36 (1), 28-44

Aldred, R. (2016) Adults' attitudes towards child cycling: a study of the impact of infrastructure, European Journal of Transport and Infrastructure Research 15, 92-115

Aldred, R. and Jungnickel, K. (2014) Why culture matters for transport policy: the case of cycling in the UK, Journal of Transport Geography 34, 78-87

Andrews, N., Clement, I. and Aldred, R. (2018) Invisible cyclists? Disabled people and cycle planning A case study of London, Journal of Transport \& Health 8, 146-156

Bonham, J. and Suh, J. (2008) Pedalling the city: intra-urban differences in cycling for the journey-towork, Road Transp. Research 17 (4), pp. 25-40

Bowles Green Ltd (2008) Engaging Ethnic Minority Communities in Cycling. Accessed at http://bowlesgreen.co.uk/wp-content/uploads/2010/07/Ethnic-Minority-Cycling-Report-BG.pdf on $4^{\text {th }}$ April 2016.

Clayton, W., Parkin, J. and Billington, C. (2017) Cycling and disability: A call for further research, Journal of Transport \& Health, in press (corrected proof)

Cox, S. (2016) Could the challenges of "biking while black" be compromising bike share outreach efforts? Better Bike Share Partnership, available at http://betterbikeshare.org/2016/11/08/difficulties-biking-black-compromise-bike-share-outreachefforts/ 
1

2

3

4

5

6

7

Department for Transport (2016) Appendix 8 Descriptive analysis of the UK and Dutch National Travel Surveys, examining propensities to cycle, in National propensity to cycle: full report with annexes, pages 334-339, available at https://www.gov.uk/government/publications/nationalpropensity-to-cycle-first-phase-development-study

Eyer, A. and Ferreira, A. (2015) Taking the Tyke on a Bike: Mothers' and Childless Women's SpaceTime Geographies in Amsterdam Compared, Environment and Planning A, 47(3), pp. 691-708 Fishman, E., Böcker, L. and Helbich, M. (2015) Adult Active Transport in the Netherlands: An Analysis of Its Contribution to Physical Activity Requirements, PLOS One:

http://dx.doi.org/10.1371/journal.pone.0121871

Fishman, E. (2016) Cycling as Transport, Transport Reviews 36(1), pp. 1-8

Flanagan, E., Lachapelle, U. and El-Geneidy, A. (2016) Riding tandem: Does cycling infrastructure investment mirror gentrification and privilege in Portland, OR and Chicago, IL? Research in Transportation Economics, http://www.sciencedirect.com/science/article/pii/S0739885915300287 Gaete-Reyes, M. (2015) Citizenship and the embodied practice of wheelchair use, Geoforum 64, 351361

Goodman, A. (2013) Walking, Cycling and Driving to Work in the English and Welsh 2011 Census: Trends, Socio-Economic Patterning and Relevance to Travel Behaviour in General, PLOS One, http://dx.doi.org/10.1371/journal.pone.0071790 Goodman, A., Brand, C., and Ogilvie, D. (2012) Associations of health, physical activity and weight status with motorised travel and transport carbon dioxide emissions: a cross-sectional, observational study, Environmental Health. August 3;11:52. doi: 10.1186/1476-069X-11-52

Goodman, A., Panter, J., Sharp, S.J. and Ogilvie, D. (2013) Effectiveness and equity impacts of townwide cycling initiatives in England: A longitudinal, controlled natural experimental study, Social Science \& Medicine 97, 228-237 Heinen, E., van Wee, B. \& Maat, K. (2010) Commuting by Bicycle: An Overview of the Literature, Transport Reviews 30(1), pp. 59-96 
Hill, D. (2015) Why are London cyclists so white, male and middle-class? Guardian Monday 12

October 2015, https://www.theguardian.com/uk-news/davehillblog/2015/oct/12/why-are-london-

cyclists-so-white-male-and-middle-class

Jones, M. (2001) Promoting cycling in the U.K.: Problems experienced by the practitioners, World

Transport Policy \& Practice, 7(3), pp.8-13

Nehme, E.K., Pérez, A., Ranjit, N., Amick, B.C. and Kohl, H.W. (2016) Sociodemographic Factors, Population Density, and Bicycling for Transportation in the United States, Journal of Physical Activity and Health, The Official Journal of the International Society for Physical Activity and Health, 13(1)

Office for National Statistics (2014) 2011 Census Analysis - Cycling to Work, available at https://www.ons.gov.uk/ons/dcp171776 357613.pdf

Palacin, R., Vigar, G. and Peacock, S. (2016) Transport Poverty and Urban Mobility. In Justice and Fairness in the City: A Multidisciplinary Approach to 'ordinary cities', edited by Simin Davoudi and Derek Bell, Bristol: Policy Press, pp. 69-84.

People for Bikes/Alliance for Biking and Walking (2016) BUILDING EQUITY, Race, ethnicity, class, and protected bike lanes: An idea book for fairer cities

Rizzo, L. Brick, JM and Park, I (2004) A minimally intrusive method of for sampling persons in random digit dial surveys, The Public Opinion Quarterly 68 (2), pp. 267-274

Sport England (2017) Active People Survey 5-10 Technical Report. Accessed 22/1/2018 from https://discover.ukdataservice.ac.uk/catalogue/?sn=8165\&type=Data\%20catalogue Stanley, J. and Vella-Brodrick, D. (2009) The usefulness of social exclusion to inform social policy in transport, Transport Policy 16(3), pp.90-96

Steinbach, R., Green, J., Datta, J. and Edwards, P. (2011) Cycling and the city: A case study of how gendered, ethnic and class identities can shape healthy transport choices, Social Science \& Medicine 72(7), pp. $1123-1130$ 
1 Van der Kloof, A., Bastiaanssen, J. and Martens, K. (2014) Bicycle lessons, activity participation and

2 empowerment, Case Studies on Transport Policy 2; 89-95

3 Wallop, H. (2016) Cycling beats golf in the new world of networking, Financial Times, September $20^{\text {th }}$

4 2016, https://www.ft.com/content/98eb4072-7a98-11e6-ae24-f193b105145e

5 Winters, M. and Teschke, K. (2010) Route preferences among adults in the near market for bicycling:

6 findings of the cycling in cities study, American journal of health promotion 25 (1), 40-47

7 Zempi, I. and Chakraborti, N.A. (2015) 'They Make Us Feel Like We're a Virus': The Multiple Impacts

8 of Islamophobic Hostility Towards Veiled Muslim Women, International Journal for Crime, Justice

9 and Social Democracy 2015 4(3): 44-56

10 Zou, G. (2004). "A modified Poisson regression approach to prospective studies with binary data."

11 American Journal of Epidemiology 159(7): 702-706

12 
Table 1: Characteristics of participants in the national sample

\begin{tabular}{|c|c|c|c|}
\hline & & $\begin{array}{c}\text { N. } \\
\text { participants }\end{array}$ & $\begin{array}{c}\text { Weighted } \\
\text { percent }\end{array}$ \\
\hline Sex & $\begin{array}{l}\text { Male } \\
\text { Female }\end{array}$ & $\begin{array}{l}321,839 \\
467,357\end{array}$ & $\begin{array}{l}49 \% \\
51 \%\end{array}$ \\
\hline Age & $\begin{array}{l}16-29 \\
30-39 \\
40-49 \\
50-59 \\
60-69 \\
70+\end{array}$ & $\begin{array}{c}81,196 \\
81,792 \\
124,711 \\
139,674 \\
157,989 \\
203,834\end{array}$ & $\begin{array}{r}22 \% \\
16 \% \\
18 \% \\
17 \% \\
13 \% \\
14 \%\end{array}$ \\
\hline Ethnicity & $\begin{array}{l}\text { White } \\
\text { Non-white }\end{array}$ & $\begin{array}{l}737,469 \\
51,727\end{array}$ & $\begin{array}{l}87 \% \\
13 \%\end{array}$ \\
\hline Disability & $\begin{array}{l}\text { No } \\
\text { Yes }\end{array}$ & $\begin{array}{l}628,966 \\
160,230\end{array}$ & $\begin{array}{l}85 \% \\
15 \%\end{array}$ \\
\hline $\begin{array}{l}\text { Co-resident } \\
\text { child age 5-15 }\end{array}$ & $\begin{array}{l}\text { No } \\
\text { Yes }\end{array}$ & $\begin{array}{l}243,102 \\
119,562\end{array}$ & $\begin{array}{l}67 \% \\
33 \%\end{array}$ \\
\hline Education & $\begin{array}{l}\text { High } \\
\text { Medium } \\
\text { Low }\end{array}$ & $\begin{array}{r}104,301 \\
46,442 \\
117,362\end{array}$ & $\begin{array}{l}40 \% \\
20 \% \\
40 \% \\
\end{array}$ \\
\hline $\begin{array}{l}\text { Car in } \\
\text { household }\end{array}$ & $\begin{array}{l}\text { No } \\
\text { Yes }\end{array}$ & $\begin{array}{l}16,002 \\
61,880\end{array}$ & $\begin{array}{l}17 \% \\
83 \%\end{array}$ \\
\hline
\end{tabular}
participants aged 24-58. 
1

2 Table 2: Cycling inequalities with respect demographic and socio-economic variables in the

3 national sample

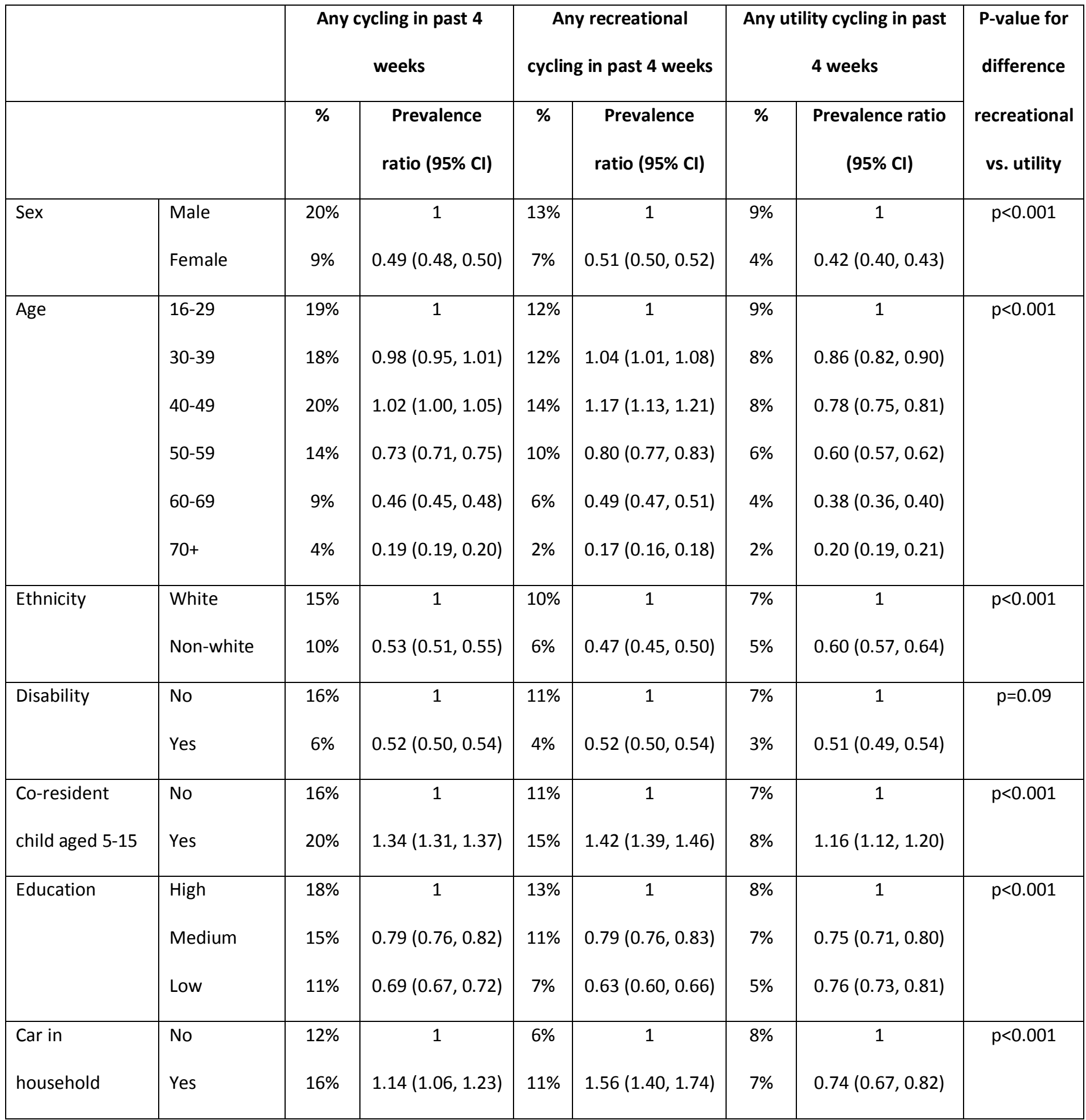

4 All $p<0.001$ in all prevalence ratios. Prevalence ratios calculated adjusting sex, age, and ethnicity; see

5 Appendix 1 for analyses additionally adjusting for the other four characteristics 
Table 3: Association between overall levels of cycling (predictor) and different measures of cycling inequality (outcome) at the level of the local authority

\begin{tabular}{|c|c|c|c|}
\hline Measure of cycling inequality & $\begin{array}{c}\text { N local } \\
\text { authorities }\end{array}$ & $\begin{array}{l}\text { Regression coefficient }(95 \% \mathrm{Cl}) \text { : } \\
\text { change in the prevalence ratio } \\
\text { per } 10 \% \text { increase in the } \% \text { adults } \\
\text { doing any cycling in the past } \\
\text { month }\end{array}$ & $\begin{array}{l}\text { p-value for } \\
\text { difference } \\
\text { recreational } \\
\text { vs. utility }\end{array}$ \\
\hline $\begin{array}{l}\text { PR for female (vs. male) for: } \\
\text { - Any cycling } \\
\text { - Recreational cycling } \\
\text { - Utility cycling }\end{array}$ & 323 & $\begin{array}{l}0.17(0.15,0.20) \\
0.14(0.11,0.17) \\
0.25(0.21,0.28)\end{array}$ & $p<0.001$ \\
\hline $\begin{array}{l}\text { PR for age 50+ (vs. age 16-49) for: } \\
\text { - Any cycling } \\
\text { - Recreational cycling } \\
\text { - Utility cycling }\end{array}$ & 324 & $\begin{array}{l}0.09(0.06,0.11) \\
0.06(0.03,0.08) \\
0.13(0.09,0.17)\end{array}$ & $p=0.002$ \\
\hline $\begin{array}{l}\text { PR for non-white (vs. white) for: } \\
\text { - Any cycling } \\
\text { - Recreational cycling } \\
\text { - Utility cycling }\end{array}$ & 155 & $\begin{array}{l}-0.03(-0.14,0.08) \\
-0.02(-0.15,0.11) \\
-0.13(-0.31,0.04)\end{array}$ & $p=0.30$ \\
\hline $\begin{array}{l}\text { PR for physical disability (vs. none) for: } \\
\text { - Any cycling } \\
\text { - Recreational cycling } \\
\text { - Utility cycling }\end{array}$ & 290 & $\begin{array}{l}0.05(0.00,0.10) \\
0.11(0.05,0.17) \\
-0.02(-0.11,0.06)\end{array}$ & $p=0.009$ \\
\hline $\begin{array}{l}\text { PR for child age 5-15 (vs. none) for: } \\
\text { - Any cycling } \\
\text { - Recreational cycling }\end{array}$ & 324 & $\begin{array}{l}-0.05(-0.13,0.02) \\
-0.07(-0.16,0.02)\end{array}$ & $p=0.53$ \\
\hline
\end{tabular}




\begin{tabular}{|c|c|c|c|}
\hline - Utility cycling & & $-0.02(-0.16,0.12)$ & \\
\hline PR for low/medium ed & & & \\
\hline - Any cycling & 317 & $-0.02(-0.08,0.04)$ & \\
\hline - Recreational cycling & & $-0.01(-0.07,0.06)$ & $p=0.06$ \\
\hline - Utility cycling & & $-0.20(-0.39,-0.02)$ & \\
\hline
\end{tabular}

$\mathrm{PR}=$ prevalence ratio. Regression analyses run with each local authority being given equal weight. Coefficients significant at $p \leq 0.05$ are shown in bold. In no case was there evidence of non-linearity, as judged by the inclusion of a quadratic term ( $p>0.05$ ). Comparisons in terms of car ownership not shown, because only $36 / 324$ local authorities met the minimum sample size criteria. 
Figure 1: Association between overall levels of cycling (predictor) and different measures of cycling inequality (outcome) at the level of the local authority
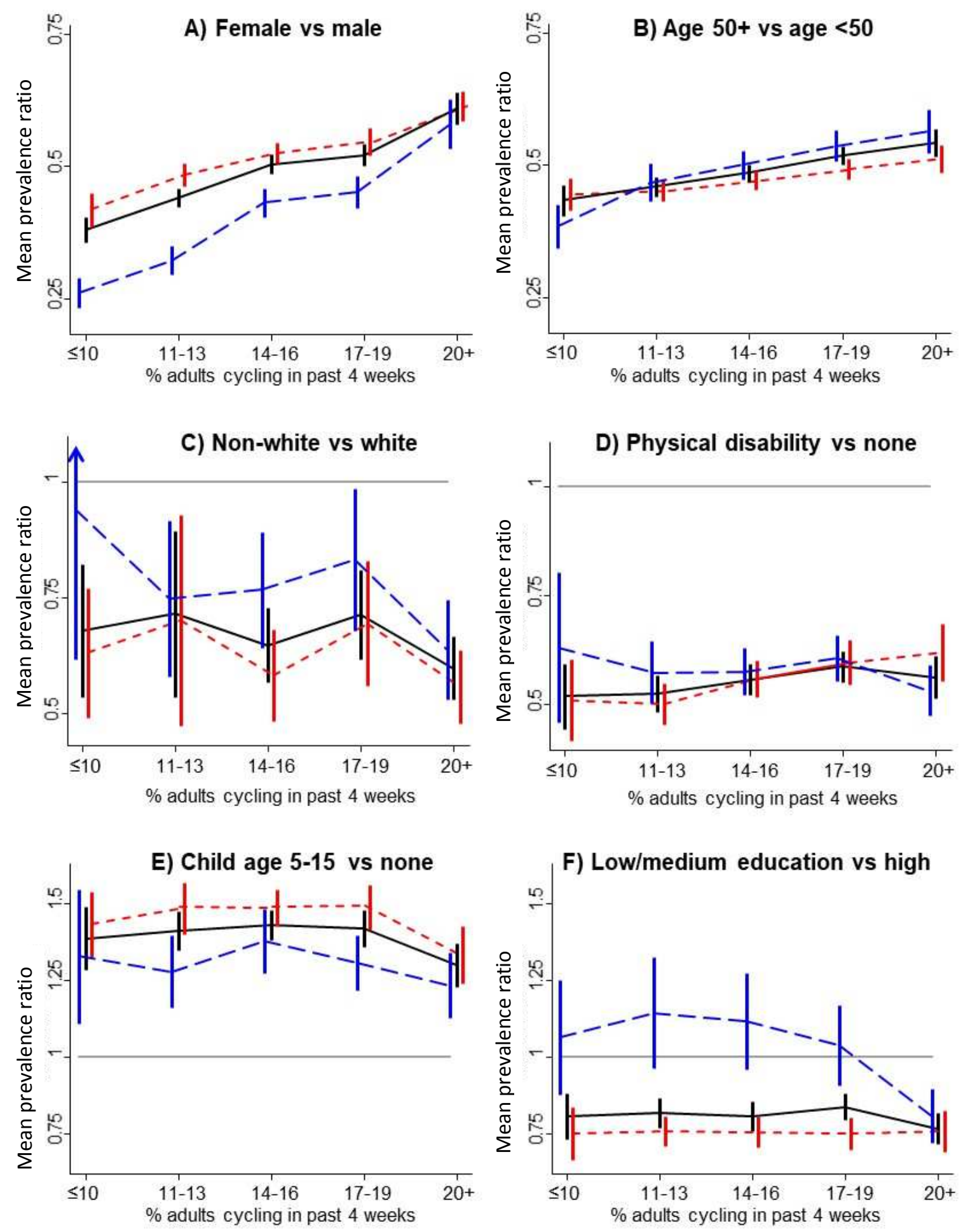
The number of local authorities varies between the six characteristics shown (see Table 3 ). In the full sample of 324 local authorities, the proportion of adults cycling in the past four weeks is $\leq 10 \%$ in $46,11-13 \%$ in 75,14 $16 \%$ in $95,17-19 \%$ in 66 , and $20 \%+$ in 42 . 


\section{Appendix 1}

Table 4 compares prevalence ratios between analyses adjusting only for sex, age, and ethnicity ('prevalence ratio 1', equivalent to those shown in the main text) and analyses that mutually adjust for all seven characteristics ('prevalence ratio 2'). These analyses are restricted to the 77,676 participants with full data for characteristics ( $9.8 \%$ of the national sample used in the main paper), i.e. the random sub- sample of participants in 2011/12 who were asked questions on both car ownership and education. Unlike in the main paper, the results for having a co-resident child age 515 are not restricted to those aged $24-58$ years, as this would prevent one being to analyse the full sample in a single model.

As Table 4 shows, in general the prevalence ratios changed very little after additionally adjusting for disability, having a co-resident child, education and car ownership. The only two exceptions were:

1. The prevalence ratio for recreational cycling aged 30-49 attenuated after further adjustment, becoming similar to that seen age 16-29. This attenuation was largely driven by adjustment for having a co-resident child age 5-15. In other words, the observed increase in recreational cycling between age 30-49 appeared to be mediated by the fact that people between these ages were more likely to have a co-resident child age 5-15.

2. The prevalence ratio for recreational cycling among those with a household car attenuated slightly after further adjustment. This attenuation was largely driven by adjustment for education. In other words, confounding by education seem to explain a small part of the association between having a household car and recreational cycling. 
Table 4: Cycling inequalities with respect demographic and socio-economic variables in the sub-sample with full data for characteristics $(\mathrm{N}=\mathbf{7 7 , 6 7 6 )}$

\begin{tabular}{|c|c|c|c|c|c|c|c|}
\hline & & Any cycling $\mathrm{i}$ & past 4 weeks & $\begin{array}{c}\text { Any recreationa } \\
\text { we }\end{array}$ & $\begin{array}{l}\text { cycling in past } 4 \\
\text { eks }\end{array}$ & Any utility cyclir & in past 4 weeks \\
\hline & & $\begin{array}{c}\text { Prevalence } \\
\text { ratio } 1(95 \% \mathrm{Cl})\end{array}$ & $\begin{array}{c}\text { Prevalence ratio } \\
2(95 \% \mathrm{Cl})\end{array}$ & $\begin{array}{c}\text { Prevalence } \\
\text { ratio } 1(95 \% \mathrm{Cl})\end{array}$ & $\begin{array}{l}\text { Prevalence ratio } \\
2(95 \% \mathrm{Cl})\end{array}$ & $\begin{array}{l}\text { Prevalence ratio } \\
\qquad 1(95 \% \mathrm{Cl})\end{array}$ & $\begin{array}{l}\text { Prevalence ratio } \\
2(95 \% \mathrm{Cl})\end{array}$ \\
\hline Sex & $\begin{array}{l}\text { Male } \\
\text { Female }\end{array}$ & $\begin{array}{c}1 \\
0.48(0.46,0.51)\end{array}$ & $\begin{array}{c}1 \\
0.49(0.46,0.51)\end{array}$ & $\begin{array}{c}1 \\
0.50(0.47,0.53)\end{array}$ & $\begin{array}{c}1 \\
0.50(0.47,0.54)\end{array}$ & $\begin{array}{c}1 \\
0.42(0.39,0.46)\end{array}$ & $\begin{array}{c}1 \\
0.43(0.40,0.47)\end{array}$ \\
\hline Age & $\begin{array}{l}16-29 \\
30-39 \\
40-49 \\
50-59 \\
60-69 \\
70+\end{array}$ & $\begin{array}{c}1 \\
0.99(0.92,1.07) \\
1.02(0.95,1.09) \\
0.63(0.59,0.69) \\
0.45(0.41,0.50) \\
0.20(0.17,0.22)\end{array}$ & $\begin{array}{c}1 \\
0.86(0.79,0.93) \\
0.89(0.83,0.96) \\
0.64(0.59,0.69) \\
0.49(0.45,0.54) \\
0.24(0.21,0.27)\end{array}$ & $\begin{array}{c}1 \\
1.07(0.97,1.18) \\
1.18(1.08,1.29) \\
0.68(0.62,0.76) \\
0.48(0.42,0.54) \\
0.17(0.15,0.20)\end{array}$ & $\begin{array}{c}1 \\
0.90(0.81,0.99) \\
0.99(0.90,1.09) \\
0.68(0.61,0.75) \\
0.52(0.46,0.59) \\
0.22(0.19,0.26)\end{array}$ & $\begin{array}{c}1 \\
0.88(0.79,1.00) \\
0.77(0.68,0.86) \\
0.55(0.49,0.62) \\
0.38(0.33,0.44) \\
0.21(0.18,0.24)\end{array}$ & $\begin{array}{c}1 \\
0.81(0.72,0.92) \\
0.74(0.66,0.84) \\
0.57(0.50,0.64) \\
0.41(0.36,0.48) \\
0.23(0.19,0.27)\end{array}$ \\
\hline Ethnicity & $\begin{array}{l}\text { White } \\
\text { Non-white }\end{array}$ & $\begin{array}{c}1 \\
0.50(0.45,0.57)\end{array}$ & $\begin{array}{c}1 \\
0.48(0.43,0.54)\end{array}$ & $\begin{array}{c}1 \\
0.45(0.39,0.52)\end{array}$ & $\begin{array}{c}1 \\
0.44(0.38,0.51)\end{array}$ & $\begin{array}{c}1 \\
0.58(0.49,0.69)\end{array}$ & $\begin{array}{c}1 \\
0.53(0.45,0.62)\end{array}$ \\
\hline Disability & $\begin{array}{l}\text { No } \\
\text { Yes }\end{array}$ & $\begin{array}{c}1 \\
0.54(0.48,0.59)\end{array}$ & $\begin{array}{c}1 \\
0.56(0.50,0.62)\end{array}$ & $\begin{array}{c}1 \\
0.52(0.46,0.59)\end{array}$ & $\begin{array}{c}1 \\
0.55(0.49,0.63)\end{array}$ & $\begin{array}{c}1 \\
0.55(0.47,0.65)\end{array}$ & $\begin{array}{c}1 \\
0.55(0.47,0.65)\end{array}$ \\
\hline
\end{tabular}




\begin{tabular}{|l|l|c|c|c|c|c|c|}
\hline Co-resident & No & 1 & 1 & 1 & 1 \\
child age 5-15 & Yes & $1.28(1.21,1.37)$ & $1.29(1.21,1.37)$ & $1.38(1.28,1.49)$ & $1.36(1.26,1.47)$ & $1.05(0.94,1.16)$ & $1.08(0.97,1.20)$ \\
\hline Education & High & 1 & 1 & 1 & 1 & 1 \\
& Medium & $0.78(0.73,0.83)$ & $0.78(0.73,0.83)$ & $0.80(0.74,0.87)$ & $0.81(0.74,0.87)$ & $0.69(0.62,0.77)$ & $0.70(0.63,0.78)$ \\
& Low & $0.69(0.65,0.73)$ & $0.70(0.66,0.74)$ & $0.63(0.58,0.68)$ & $0.65(0.60,0.70)$ & $0.74(0.68,0.82)$ & $0.74(0.67,0.81)$ \\
\hline Car in & No & 1 & 1 & 1 & 1 & 1 \\
household & Yes & $1.15(1.06,1.24)$ & $1.06(0.98,1.15)$ & $1.57(1.41,1.76)$ & $1.43(1.28,1.60)$ & $0.74(0.67,0.83)$ & $0.71(0.64,0.79)$ \\
\hline
\end{tabular}

Prevalence ratio 1 is calculated adjusting for sex, age, and ethnicity. Prevalence ratio 2 is calculated simultaneously adjusting for all seven characteristics. These analyses are restricted to the 77,676 individuals with full data on all characteristics. Unlike in the main paper, the analyses for having a co-resident child age 5-15 are not restricted to those aged $24-58$. 